\begin{tabular}{|c|c|c|}
\hline $\begin{array}{l}\text { JURNALPENELITIAN KEBIDANAN } \\
\text { \& KESPRO }\end{array}$ & VOL. 1 NO. 2 & $\begin{array}{c}\text { EDITION: NOVEMBER } 2018- \\
\text { APRIL } 2019\end{array}$ \\
\hline & http://ejournal.delihusada.ac.id/index.php/JPKM & \\
\hline
\end{tabular}

\title{
PENGARUH STIMULASI PEMBERIAN TABLET HISAP VITAMIN C TERHADAP PENINGKATAN SEKRESI SALIVA PADA PASIEN GAGAL GINJAL KRONIK YANG MENJALANI TERAPI HEMODIALISA DI RS UMUM SEMBIRING
}

\author{
Rostiodertina Girsang, Dewi Tiansa Barus \\ Institut kesehatan Deli Husada, Jl. Besar No. 77 Deli Tua \\ email: rostiodertinagirsang1@gmail.com
}

\begin{abstract}
Chronic kidney failure is a progressive and irreversible decline in kidney function, in which the body is unable to maintain fluid balance and electrolyte metabolism. In practice, patients must limit the liquid diet to prevent complications. To reduce patient complaints, the action that can be done is to stimulate the salivary glands with chemical stimulation using acidic vitamin $C$ lozenges. The purpose of this study was to determine the stimulating effects of vitamin $C$ lozenges to increase salivary secretion in patients with chronic renal failure undergoing hemodialysis therapy at Sembiring General Hospital. This study used a Pre-experimental design with a pretest-posttest design. The sample amounted to 48 respondents, using Purposive Sampling techniques. Based on analysis conducted found significant differences amount of secretion of saliva before and after found a significant increase in the secretion of saliva between pretest saliva and posttest conclusion, the stimulation of the provision of lozenges vitamin $C$ has the effect of increasing salivary secretion in patients with chronic kidney failure undergoing hemodialysis therapy at Sembiring General Hospital.
\end{abstract}

Keywords: Stimulation, Saliva Secretion, Chronic Kidney Failure.

\section{PENDAHULUAN}

Salah satu penyakit yang terus meningkat keparahannya adalah penyakit gagal ginjal kronik atau disebut juga dengan Chronic Kidney Disease(CKD) / End Stage Renal Disease (ESRD). Pada saat menderita gagal ginjal kronik, maka metabolisme tubuh orang tersebut kurang baik dan gagal menjaga keseimbangan cairan serta elektrolit sehingga terjadi peningkatan ureum dan kreatin pada orang tersebut (Smeltzer \& Bare, 2010).

Dari semua negara, bahwa penyakit gagal ginjal dari tahun ke tahun terjadi peningkatan yang sangat tinggi. Peningatan yang terjadi di Indonesia mencapai 300.000 lebih yang mengalami penyaki gagal ginjal, dan dari 300.000 orang tersebut hanya 25.000 orang yang dapat tertangani tenaga medis dan 80 persen dari pasien tersebut tidak mendapatkan pengobatan sama sekali" (Susalit, 2012).

Data diatas sejalan dengan data yang ada pada mortality WHO South Asia Region pada tahun 2010-2012, yang menyatakan bahwa peningkatan yang terjadi pada gagal ginjal kronis mencapai 250.217 orang. Apabila tidak ditangani dengan baik kualitas hidup pasien yang menderita penyakit gagal ginjal akan mengalami kerusakan fungsi ginjal, bahkan akumulasi toksin uremia yang ada pada darah dapat menyebabkan kematian" (Suwitra, 2006).

Terapi dalam penggantian ginjal adalah usaha yang dapat kita lakukan untuk mengatasi masalah tersebut. Terapi yang dimaksud adalah terapi hemodalisa, terapi peritoneal dialisis ataupun transplantasi ginjal 


\begin{tabular}{c|c|c}
\hline $\begin{array}{c}\text { JURNALPENELITIAN KEBIDANAN } \\
\text { \& KESPRO }\end{array}$ & VOL. 1 NO. 2 & $\begin{array}{c}\text { EDITION: NOVEMBER 2018 - } \\
\text { APRIL 2019 }\end{array}$ \\
\cline { 1 - 2 } & http://ejournal.delihusada.ac.id/index.php/JPKM & \\
\cline { 2 - 2 } RECEIVED: 20 JANUARI 2019 & ACCEPTED: 28 APRIL 2019 \\
\hline
\end{tabular}

(Rahardjo dkk, 2006). Proses hemodalisa yang singkat dan lebih praktis dalam mengeluarkan zat - zat dengan berat molekul rendah menjadi terapi yang banyak dipilih oleh pasien - pasien yang mengalami penyakit gagal ginjal (Ignatavicius \& Workman, 2006).

Untuk mencegah timbulnya penyakit kardiovaskuler, hipertensi, edema paru akut dan gagal ginjal kongestif, maka pasien yang mengalami penyakit gagal ginjal kronik harus melakukan pembatasan cairan agar mencegah terjadinya kelebihan cairan. Namun pembatasan cairan tersebut dapat menyebabkan produksi saliva menurun dan akan terjadi kekacauan hormonal, perubahan sosial, psikologi serta rasa haus (Bots, et al. 2005).

Hal yang umum terjadi pada pasien gagal ginjal adalah Xerostomia. Keadaan tersebut dapat membuat kualitas dan kenyamanan pasien menurun karena kesehatan mulut yang sangat berpengaruh kepada status nutrisi pasien. Melakukakan rangsangan terhadap kelenjar saliva seperti rangsang mekanis, neuronal rasa sakit, protesa atau kimiawi dapat mengurangi keluhan pasien (Bots, et al., 2005).

Vitamin C merupakan faktor mekanis dalam merangsang kelenjar saliva dengan cara menghisapnya, faktor kimiawi yang dapat merangsang kelenjar saliva yaitu rasa asam, manis, asin, pahit dan juga pedas, melalui sistem saraf autonom/simpatis maupun parasimpatis merupakan faktor neoronal. Stress yang dialami dari faktor psikis dapat menghambat sekresi saliva dan dapat menstimulasi sekresi saliva dengan pemakaian protesa (Greenberg, et al., 2008).

Asam akarbonat ataupun yang sering disebut dengan Vitamin $\mathrm{C}$ adalah salah satu Vitamin yang larut dalam air dan dapat meningkatkan sekresi saliva. Dimana terangsang karena adanaya sensasi rasa asam reseptor memulai impuls pada saraf aferen dan kemudian informasi dibawa langsung ke pusat pada medulla batang otak. Sehingga akan mengirim melalui saraf otonom untuk meningkatkan kelenjar saliva (Greenberg, et al., 2008).

Yang memiliki peran penting dalam sekresi saliva adalah Inervasi saraf yang dapat mengakibatkan jumlah besar sekresi liur dengan kandungan organik yang rendah.sekresi disertai dengan vasodilatasi pada kelenjar yang dapat menyebabkan pelepasan VIP (Vasoactive Intestine Polipeptide) yang merupakan sebagian neuron parasimpatik pasca ganglion (Greenberg, et al., 2008).

\section{METODE}

Jenis penelitian yang digunakan peneliti dalam penelitian ini adalah bersifat PreExperimental dengan menggunakan pre test and post test design. Pre-eksperimental design menggunakan rancangan penelitian one group pre-test post-test. Populasi yang dipilih peneliti dalam penelitian ini sebanyak 55 orang dengan menggunakan purposive samplingdan jumlah sampel sebanyak 48 orang dengan kriteria penderita gagal ginjal kronik, pasien yang sedang hemodialisa, usia $18 \geq 70$ tahun, pemberian normal Vitamin C pada pasien gagal ginjal kronik $200 \mathrm{mg}$.

Dalam pengumpulan data, peneliti menggunakan cara Beaker untuk mengetahui jumlah saliva. Sedangkan analisa data yang digunakan oleh peneliti menggunakan uji paired sample t-test dengan menggunakan computer untuk menilaii apakah ada pengaruh pemberian Vitamin $\mathrm{C}$ terhadap peningkatan sekresi saliva pada penderita Gagal Ginjal Kronik.

\section{HASIL DAN PEMBAHASAN}

Tabel 1. Data Umur Responden

\begin{tabular}{ccc}
\hline Umur & $\mathbf{n}$ & $\mathbf{\%}$ \\
\hline $\mathbf{1 8 - 3 0}$ & 4 & 8,3 \\
$\mathbf{3 1 - 4 1}$ & 9 & 39,5 \\
$\mathbf{4 2 - 5 6}$ & 14 & 29,1 \\
$\mathbf{5 7 - 6 9}$ & 4 & 8,3 \\
$\mathbf{2} \mathbf{7 0}$ & 7 & 14,5 \\
Jumlah & 48 & 100 \\
\hline
\end{tabular}




\begin{tabular}{|c|c|c|}
\hline $\begin{array}{l}\text { JURNALPENELITIAN KEBIDANAN } \\
\text { \& KESPRO }\end{array}$ & VOL. 1 NO. 2 & $\begin{array}{l}\text { EDITION: NOVEMBER } 2018- \\
\text { APRIL } 2019\end{array}$ \\
\hline & http://ejournal.delihusada.ac.id/index.php/JPKM & \\
\hline RECEIVED: 20 JANUARI 2019 & REVISED: 24 MARET 2019 & ACCEPTED: 28 APRIL 2019 \\
\hline
\end{tabular}

Berdasarkan tabel 1 dapat dilihat kalau responden tertinggi pada penelitian ini yaitu pada kategori umur 44-56 tahun sebanyak 14 orang $(29,1 \%)$.

Tabel 2. Data Jenis Kelamin

\begin{tabular}{lcc}
\hline Jenis Kelamin & $\mathbf{n}$ & \% \\
\hline Laki-laki & 31 & 64,6 \\
Perempuan & 17 & 35,4 \\
$\quad$ Jumlah & 48 & 100 \\
\hline
\end{tabular}

Berdasarkan tabel 2 dapat dilihat kalau responden tertinggi dalam penelitian ini pada kategori jenis kelamin yaitu pada laki - laki sebanyak 31 orang $(64,4 \%)$.

Tabel 3. Data Pekerjaan Responden

\begin{tabular}{lcc}
\hline Jenis Kelamin & $\mathbf{n}$ & $\mathbf{\%}$ \\
\hline IRT & 11 & 22,9 \\
Petani & 6 & 12,5 \\
Wiraswasta & 22 & 45,8 \\
PNS & 9 & 10,0 \\
$\quad$ Jumlah & 48 & 100 \\
\hline
\end{tabular}

Berdasarkan tabel 3 dapat dilihat kalau responden tertinggi dalam penelitian ini pada kategori pekerjaan yaitu pada wiraswasta sebanyak 22 orang $(45,8 \%)$.

Tabel 4. Data Lama Menjalani Hemodialisa

\begin{tabular}{ccc}
\hline Lama (Tahun) & $\mathbf{n}$ & $\mathbf{\%}$ \\
\hline$<\mathbf{1}$ & 7 & 14,6 \\
$\mathbf{1 - 2}$ & 27 & 56,3 \\
$>\mathbf{2}$ & 14 & 29,2 \\
Jumlah & 48 & 100 \\
\hline
\end{tabular}

Berdasarkan tabel 4 dapat dilihat kalau responden tertinggi pada penelitian ini pada kategori lama menjalani homodalisa yaitu pada lama menjalani HD selama 1-2 tahun sebanyak 27 orang $(56,3 \%)$. Adapun penggunaan Hemodialisa Per Minggu yang sering di jalani seluruh pasien gagal ginjal kronik sebanyak 48 orang sebesar $100 \%$.

Tabel 6. Data Jumlah Saliva Sebelum Menghisap Viitamin C

\begin{tabular}{lll}
\hline Jumlah Saliva & $\mathbf{n}$ & $\mathbf{\%}$ \\
\hline $\mathbf{0 . 2}$ & 3 & 6.3 \\
$\mathbf{0 . 3}$ & 12 & 25.0 \\
$\mathbf{0 . 4}$ & 15 & 31.3 \\
$\mathbf{0 . 5}$ & 11 & 22.9 \\
\hline
\end{tabular}

\begin{tabular}{lll}
\hline Jumlah Saliva & $\mathbf{n}$ & $\mathbf{\%}$ \\
\hline $\mathbf{0 . 6}$ & 5 & 10.4 \\
$\mathbf{0 . 7}$ & 2 & 4.2 \\
Jumlah & 48 & 100 \\
\hline
\end{tabular}

Jumlah saliva sebelum menghisap vitamin $C$ rata-rata 0,4 sebanyak 15 orang sebanyak $31,3 \%$.

Tabel 7. Data Jumlah Saliva Setelah Menghisap Vitamin C

\begin{tabular}{lll}
\hline Jumlah Saliva & $\mathbf{n}$ & $\mathbf{\%}$ \\
\hline $\mathbf{1 . 7}$ & 2 & 4.2 \\
$\mathbf{1 . 8}$ & 5 & 10.4 \\
$\mathbf{1 . 9}$ & 7 & 14.6 \\
$\mathbf{2 . 0}$ & 12 & 25.0 \\
$\mathbf{2 . 1}$ & 9 & 18.8 \\
$\mathbf{2 . 2}$ & 7 & 14.6 \\
$\mathbf{2 . 3}$ & 4 & 8.3 \\
$\mathbf{2 . 4}$ & 1 & 2.1 \\
$\mathbf{2 . 5}$ & 1 & 2.1 \\
Jumlah & 48 & 100 \\
\hline
\end{tabular}

Jumlah saliva setelah menghisap vitamin C mengalami peningkatan rata-rata 2,0 sebanyak 12 orang sebesar $25 \%$. Adapun terkait pengaruh Pemberian Vitamin C Terhadap peningkatan sekresi saliva dinyatakan dalam tabel berikut.

Tabel 8. Data Jumlah Saliva sebelum dan sesudah pemberian vitamin $\mathrm{C}$

\begin{tabular}{lllll}
\hline Variabel & Mean & N & SD & SE \\
\hline Sebelum & 0,419 & 48 & 0,1232 & 0,0178 \\
Sesudah & 2,044 & 48 & 0,1785 & 0,0258 \\
\hline
\end{tabular}

Menjelaskan tentang jumlah saliva sebelum menghisap vitamin C Mean 0,419, dengan Standar Deviasi 0,1232, Standar Eror 0,0178 sesudah menghisap Vitamin C Mean 2,044 dengan Standar Devisiasi 0,1785, dan Standar Eror 0,0258 terlihat perbedaan mean antara sebelum dan sesudah menghisap Vitamin C adalah 1,625 maka dapatdisimpulkan ada perbedaan antara sebelum dan sesudah menghisapVitamin $\mathrm{C}$.

Tabel 9. Pengaruh Pemberian Vitamin $C$ Terhadap peningkatan Sekresi saliva

\begin{tabular}{llll}
\hline Mean & SD & SE & Sig \\
\hline $\mathbf{- 1 , 6 2 5 0}$ & 0,2088 & 0,0301 & 0,000 \\
\hline
\end{tabular}




\begin{tabular}{|c|c|c|}
\hline $\begin{array}{l}\text { JURNALPENELITIAN KEBIDANAN } \\
\text { \& KESPRO }\end{array}$ & VOL. 1 NO. 2 & $\begin{array}{l}\text { EDITION: NOVEMBER } 2018- \\
\text { APRIL } 2019\end{array}$ \\
\hline & http://ejournal.delihusada.ac.id/index.php/JPKM & \\
\hline RECEIVED: 20 JANUARI 2019 & REVISED: 24 MARET 2019 & ACCEPTED: 28 APRIL 2019 \\
\hline
\end{tabular}

Dari pengaruh pemberian vitamin $\mathrm{C}$ didapatkan kesimpulan terdapat pengaruh pemberian vitamin $\mathrm{C}$ dalam meningkatkan sekresi saliva. Berdasarkan hasil uji Paired Sample $\mathrm{T}$ test yang dilakukan oleh peneliti komparasi sekresi saliva postest dan pretest. Hasil yang didapatkan oleh peneliti tersebut dapat disimpulkan stimulasi pemberian tablet hisap vitamin $\mathrm{C}$ berpengaruh dalam meningkatkan sekresi saliva pada pasien Gagal Ginjal Kronik yang menjalani terapi hemodialisa.

Hasil penelitian yang telah dilakukan peneliti bahwa penelitian ini sejalan dengan penelitian yang telah dilakukan oleh Utoyo dan dkk pada tahun 2016 bahwa hasil uji Paired Sample $T$ test sekresi saliva postest dan pretest kelompok intervensi didapatkan kesimpulan bahwa stimulus pemberian tablet hisap vitamin $\mathrm{C}$ berpengaruh dalam meningkatkan sekresi pada pasien Gagal Ginjal Kronik.

Hasil penelitian yang telah dilakukan peneliti bahwa penelitian ini sejalan dengan penelitian yang telah dilakukan oleh Greenberg pada tahun 2008, dimana dalam penelitian tersebut menyatakan bahwa ketika mulut terangsang oleh sensasi rasa asam, reseptor akan memulai impuls di saraf aferen dan akan membawa informasi langsung ke pusat saliva di medulla batang otak sehingga pusat saliva akan mengirim impuls melalui saraf otonom ke kelenjar saliva untuk meningkatkan sekresi saliva. Inervasi saraf parasimpatik memegang peran utama stimulus sekresi saliva menyebabkan sekresi liur cair dalam jumlah besar dengan kandungan bahan organik yang rendah.Sekresi ini disertai oleh vasodilatasi mencolok pada kelenjar, yang disebabkan oleh pelepasan VIP (Vasoactive Intestine Polipeptide) yang merupakan co-transmitter dengan asetilkolin pada sebagian neuron parasimpatis pasca ganglion.

\section{KESIMPULAN}

Berdasarkan penelitian yang dilakukan oleh peneliti yang dilakukan terhadap 48 responden yang menjalani terapi hemodialisa di Rumah Sakit Umum Sembiring Kec. Delitua Kab. Deliserdang Tahun 2018 menunjukkan hasil bahwa adanya peningkatan sekresi saliva yang signifikan antara sebelum dan sesudah menghisap Vitamin $C$ pada pasien yang menjalani terapi hemodialisa, Hasil analisa data yang dilakukan didapatkan adanya perbedaan yang bermakna antara jumlah sekresi saliva sebelum dan setelah pemberian tindakan menghisap Vitamin $\mathrm{C}$.

Ada pengaruh dari stimulasi pemberian tablet hisap Vitamin $\mathrm{C}$ terhadap peningkatan sekresi saliva pasien gagal ginjal kronik yang menjalani terapi hemodialisa.

\section{DAFTAR PUSTAKA}

Bots et al. (2013). The Management of Xerostomia in Patients on Haemodialysis: Comparison of Artificial Saliva and Chewing Gum.

Greenberg, M.S., Glick, M., \& Jonathan, A.S. (2015). Salivary glan desease. Burket's oral medicine diagnosis and treatment. 11th ed. Hamilton: BC Decker Inc.

Haroen ER. 2015. Pengaruh stimulus pengunyahan dan pengecapan terhadap kecepatan aliran dan $\mathrm{pH}$ saliva. J Kedokteran Gigi Universitas Indonesia. 9(1) : 29-34.

Ignatavicius, D.D., \& Workman, M.L. (2011). Medical Surgical Nursing: Critical Thinking for Collaborative Care (5th Edition). St Louis Missouri: Elsevier Saunders.

Smeltzer, S., \& Bare, B. (2010). Buku Ajar Keperawatan Medikal Bedah Brunner \& Suddarth. Ed

Susalit, E dkk. (2012). Buku Ajar Ilmu Penyakit Dalam II. Jakarta : Balai penerbit FKUI. 


\begin{tabular}{c|c|c|}
\hline $\begin{array}{c}\text { JURNALPENELITIAN KEBIDANAN } \\
\text { \& KESPRO }\end{array}$ & VOL. 1 NO. 2 & $\begin{array}{c}\text { EDITION: NOVEMBER 2018 } \\
\text { APRIL } 2019\end{array}$ \\
\hline & $\frac{\text { http://ejournal.delihusada.ac.id/index.php/JPKM }}{\text { REVISED: } 24 \text { MARET } 2019}$ & \\
\cline { 2 - 3 } RECEIVED: 20 JANUARI 2019 & ACCEPTED: 28 APRIL 2019 \\
\hline
\end{tabular}

Suwitra, K. (2016). Buku Ajar Ilmu Penyakit Dalam. Edisi IV, Jilid I. Jakarta: Pusat Penerbitan Departemen Ilmu Penyakit Dalam FKUI.
Utoyo, B dkk. (2016). Jurnal Pengaruh Stimulasi Pemberian Tablet Hisap Vitamin Cterhadap Peningkatan Sekresi Saliva Pada Pasien Gagalginjal Kronik Yang menjalani Terapi Hemodialisa 